\title{
Bathing wipes, a valuable hygiene option for frail older persons at home: a proof-of-concept study
}

\author{
AUTHORS \\ VICKIE ARCHER BN ${ }^{1}$ \\ WENDY SMYTH PhD2,3 \\ CATE NAGLE PhD2,3
}

\section{CORRESPONDING AUTHOR}

WENDY SMYTH Townsville Institute of Health Research and Innovation, Townsville University Hospital, 100 Angus Smith Drive, Douglas Queensland Australia 4814. Email: wendy.smyth@health.qld.gov.au

\section{ABSTRACT}

Objectives: To explore experiences and attitudes of frail older persons to using bathing wipes as a hygiene option at home.

Methods: A descriptive, exploratory study was conducted with older clients who required hygiene assistance post hospital discharge and consented to trial bath wipes. Client participants or their carer completed a verbal questionnaire administered via telephone. Descriptive statistics summarised the quantitative data and closed-ended questions were analysed using content analysis.

Results: Thirty-seven of the 49 consented participants used the bathing wipes at home. There was high level of agreement that bathing wipes were fit for purpose and participants indicated that they were suitable to use to supplement assisted showers.

Conclusion: The use of bathing wipes provides an acceptable hygiene option and can support autonomy of frail, older persons, while reducing the risk of falls from wet floors. Bathing wipes are of use to persons who have not yet regained independence with showering and/or are awaiting bathroom modifications installed.
What is already known about the topic?

-Wet floors associated with showering unassisted, can be a falls hazard to elderly persons attempting to regain independence.

- Transition care programs offered for elderly clients returning to their own home post hospital discharge are limited in scope and duration.

- Falls in frail, older people are common, with adverse consequences for the individual and the health system.

\section{What this paper adds}

- Bath wipes were well accepted by elderly clients as an alternative to showering without assistance.

- Bath wipes can be used by the individual on a short-term basis while they regain independence with hygiene, while they wait for bathroom modifications, or they can be used longer term.

Keywords: Personal hygiene; falls prevention; frailty; transitional care 


\section{BACKGROUND}

Following discharge from Australian hospitals, many frail older clients receive assistance with personal hygiene three times weekly for a short-term period supported by a Commonwealth-funded Transition Care Package. This is consistent with the Government's and society's preference for supporting people to age in home rather than go into residential aged care. ${ }^{1}$ People have different personal hygiene preferences and practices, related to their wish to feel refreshed, society's expectations, and to regain independence. ${ }^{2,3}$ In hot, humid tropical regions personal hygiene requirements can escalate. However, not all people have someone to assist with hygiene on days when Transition Care is not provided, nor can they necessarily afford additional in-home care, expensive medical aid equipment and/or bathroom modifications to enable independence with showering.

Bathing wipes are pre-packaged disposable washcloths that contain a quick drying cleansing emollient and may be a safe, cost-effective alternative to showering. No other equipment is required, and personal hygiene can be undertaken anywhere convenient to the user. They are suitable for fragile skin, ${ }^{2,4}$ their use may reduce the significant falls risk of elderly persons living in the community, ${ }^{5}$ and the specific falls risk associated with wet bathroom floors for people with gait or balance deficits. ${ }^{6}$ Whilst one goal of the Transition Care Package is to optimise clients' self-management skills, ${ }^{7}$ bathing wipes are potentially available on an ongoing basis for individuals who do not regain independence with showering. Whether such a change in bathing practices is acceptable to older persons in community settings is unknown. Groven et al. recommended that future research about bathing wipes should explore patients' perspectives, satisfaction and experiences in order to support patient centred quality care. ${ }^{4}$ This study aimed to explore enablers and barriers to frail older persons using bathing wipes to assist with their hygiene in the community setting.

\section{METHOD}

\section{STUDY DESIGN}

A descriptive, exploratory study design using questionnaires was employed.

\section{STUDY OBJECTIVES}

The study objectives were to:

1. Explore Transition Care Program clients' experiences and attitudes to using bathing wipes; and

2. Explore whether these clients intended to continue using bathing wipes at the conclusion of the Transition Care Program.

\section{SETTING AND PARTICIPANTS}

The study took place in the community setting of a regional city in north Queensland, Australia. The client participants were frail, older people recently discharged from hospital on a Transition Care Program. These individuals had been assessed as requiring hygiene assistance and had consented to trial the bathing wipes at home. Other inclusion criteria were that they resided within the local community and were contactable by telephone. A carer could answer the questions on their behalf. After consenting to participate, clients were provided with a package of bathing wipes and education. Additional bathing wipes were provided by the community service for the Program. A copy of the questionnaire was given to clients prior to their discharge so that they were familiar with the questions that would be asked via telephone. Organisational ethics approval was obtained (HREC/18/QTHS162).

\section{THE INTERVENTION}

The intervention was a packet of disposable bathing wipes ('Bath in bed wipes', Reynard Health Supplies). Each packet contained eight wipes, the equivalent of one bath. Each bath wipe measured $33 \mathrm{~cm}$ by $23 \mathrm{~cm}$; the packet could be heated or cooled prior to use.

\section{DATA COLLECTION}

The researcher telephoned the clients at the nominated time, approximately three weeks post hospital discharge, and asked the questions from the previously provided questionnaire. The questionnaire comprised a combination of 5-point Likert scale and questions using free text; it took less than 10 minutes to complete.

\section{DATA ANALYSIS}

Binary and categorical data were summarised using frequencies and percentages. Free text responses were analysed using content analysis.

\section{RESULTS}

Fifty-two clients (from a potential 73) were recruited over a 12-month period (February 2019 - January 2020). Three were excluded from data analysis because they were either discharged to a residential aged care facility (1), declined the Transition Care Package after consenting (1), or declined to answer the questions by telephone (1).

All participants had some type of bathing support such as grab rails or shower chairs, and 20 (40.8\%) expressed concerns about falling. Three quarters (37/49, 75.5\%) participants used the bathing wipes following hospital discharge. Reasons for not using the bathing wipes (12/49) were mixed and the most common included: contented with having second-daily support through the Program, family assistance provided 
TABLE 1: RESPONSES FROM PARTICIPANTS ( $\mathrm{N}=30$ ): LEVEL OF AGREEMENT WITH STATEMENTS ABOUT THE BATHING WIPES

\begin{tabular}{|c|c|c|c|c|c|}
\hline Statement & $\begin{array}{r}\text { Strongly } \\
\text { agree }\end{array}$ & Agree & $\begin{array}{l}\text { Neither } \\
\text { agree nor } \\
\text { disagree }\end{array}$ & Disagree & $\begin{array}{l}\text { Strongly } \\
\text { disagree }\end{array}$ \\
\hline The bathing wipes were easy to use & 7 & 23 & 0 & 0 & 0 \\
\hline I liked using the bathing wipes & 7 & 21 & 2 & 0 & 0 \\
\hline I felt clean after using the bathing wipes & 7 & 23 & 0 & 0 & 0 \\
\hline My skin felt moisturised after using the bathing wipes & 6 & 19 & 5 & 0 & 0 \\
\hline $\begin{array}{l}\text { I think the bathing wipes are a satisfactory alternative to } \\
\text { having a shower }\end{array}$ & 7 & 18 & 3 & 2 & 0 \\
\hline
\end{tabular}

on alternate days, or clients regained their independence quickly. The reasons why seven participants could not provide responses about their experience were: used the bathing wipes in the same way as they would use a facecloth/ washer in the shower (5); inadequate supply (1); unsuited to telephone interview (1).

From the responses to the Likert-scale statements, it is evident that participants who used the bathing wipes were satisfied with their attributes. There were no 'strongly disagree' responses to any of the statements. Participants reported: they liked using the wipes; they were easy to use; they felt clean and their skin felt moisturised after using the wipes; and the wipes were an acceptable alternative to showering (for all but two participants). (Refer to Table.) Most respondents' (22/30) prior hygiene routine was daily showers.

When asked about the most favourable aspects of using the bathing wipes, responses included: convenience (11); a fantastic alternative when not feeling up to showering (5); ease of use (4); easy to heat (3); and refreshing (2). The majority of those who used the bathing wipes (23/37, 62\%) could not identify anything they did not like about the product. Seven participants offered comments that indicated a level of dissatisfaction with the product: the packets were difficult to open (3); even though the bathing wipes were effective, they were still not as good as water (2); it would be preferred if the wipes could be flushed down the toilet (1); the wipes were twice as big as they needed to be (1).

Two-thirds (24/37, 65\%) participants said they received adequate supplies of the product. One participant who had received insufficient supply did not think bathing wipes were an appropriate alternative to showering. All participants said they would use the product in the future if they were unwell or not able to access their shower. They were unsure as to how much they would be prepared to pay for bathing wipes, with answers ranging from "no idea" to up to $\$ 4$.oo per packet.

\section{DISCUSSION}

Despite initiatives to reduce falls, fall-related injury remains a major public health concern, with significant older persons who fall at home requiring hospitalisation., ${ }^{3,8,9} \mathrm{~A}$ fear of falling, as expressed by many participants can increase fall risk..$^{10}$ Although clients still preferred showering, they provided many examples of situations when the bathing wipes would be safer and more convenient. It is important to design systems which incorporate the variation in preferences for personal hygiene options. ${ }^{11,12}$ Bathing wipes could be an autonomous and sustainable option for meeting basic hygiene preferences long-term, or in the shorter term while clients wait for permanent bathroom modifications or regain their independence. ${ }^{3}$ Lack of adequate supplies of the product was a barrier during the study period, and continued usage may be limited due to difficulties for frail older people purchasing bathing wipes. The cost to the general public for the brand of bathing wipes used in this study is slightly higher than it was to the hospital, however, the bathing wipes are now available online, within the upper price limit clients indicated they would be willing to pay. A limited range of comparable products is available in select pharmacies and medical supply stores as well as online, although some older people may still find it difficult to purchase them.

From the perspectives of the participants, some practical difficulties were experienced using the wipes. However overall, the wipes were favourably received. For the one-third of frail older Australians who fall each year, 5 the bathing wipes option may be a viable, low-cost, safe option for personal hygiene.

\section{IMPLICATIONS FOR RESEARCH, POLICY, AND PRACTICE}

This is novel research, exploring the experiences of frail, older persons' use of bathing wipes to assist with personal hygiene in their own homes. Future research needs to explore the acceptability of bathing wipes across different health settings and patient groups and explore the long-term impact of the use of bathing wipes on the incidence of falls and on skin integrity. 
Nurses and carers, who are aware of bathing wipes and how to instruct patients as to their correct use, can inform clients about choices which may improve their independence with personal hygiene. With broader awareness, similar products could provide an alternative, safe, cost effective hygiene option for people living in the community longer-term, and providers of subsidised aged-care packages.

Acknowledgements: We acknowledge the contribution of Helen Murray, Nurse Unit Manager, in the initial design of the study and for supporting implementation. We also acknowledge the contribution of Gabrielle Oswin, Clinical Nurse, who assisted with data collection. We thank the clients who participated in the study, and staff of the nongovernment organisation who ensured a supply of the products and assisted the participants following their discharge from hospital.

Funding Support: This study was unfunded. Bath wipes were sourced as part of the Transition Care Program.

Declaration of conflicting interests: No conflicts of interest to be declared.

\section{REFERENCES}

1. Pagone T, Briggs L. Royal Commission into Aged Care Quality and Safety, Final Report: Care, Dignity and Respect. Vol. 1 Summary and recommendations. Commonwealth of Australia. Canberra. 2021

2. Sheppard CM, Brenner PS. The effects of bathing and skin care practices on skin quality and satisfaction with an innovative product. J Gerontol Nurs. 2000; 26(10): 36-45.

3. Olsson A, Berglöv A, Sjölund BM. "Longing to be independent again" - a qualitative study on older adults' experiences of life after hospitalization. Geriatr Nurs. 2020; 41(6); 942-948. Available from: https://doi.org/10.1016/j.gerinurse.2020.07.007.

4. Groven FM, Zwakhalen SM, Odekerken-Schroder G, Joosten EJ, Hamers JP. How does washing without water perform compared to the traditional bed bath: a systematic review. BMC Geriatr. 2017; 17(1): 31. Available from: https://doi.org/10.1186/s12877-017-0425-4

5. Australian Commission on Safety and Quality in Health Care (ACSQHC). Preventing falls and harm from falls in older people. Best practice guidelines for Australian community care. Australian Commission on Safety and Quality in Healthcare. Sydney. 2009

6. Nowak A, Hubbard RE. Falls and frailty: lessons from complex systems. J R Soc Med. 2009; 102(3): 98-102. Available from: https://doi.org/10.1258/jrsm.2009.080274

7. Australian Government Department of Health. Transition Care Programme Guidelines. Commonwealth of Australia. Canberra. 2015. Available from: https://agedcare.health.gov.au/sites/g/ files/net1426/f/documents/02 2016/transition care guidelines.pdf

8. Watson W, Clapperton A, Mitchell R. The incidence and cost of falls injury among older people in New South Wales 2006/07. NSW Department of Health. Sydney. 2010

9. While A. Falls and older people: preventative interventions. Br J Community Nurs. 2020; 25(6): 288-292. Available from: https://doi.org/10.12968/bjen.2020.25.6.288
10. Young W, Williams A. How fear of falling can increase fall-risk in older adults: applying psychological theory to practical observations. Gait Posture. 2015; 41(1): 7-12. Available from: https://doi.org/10.1016/j.gaitpost.2014.09.006

11. Veje PL, Chen M, Jensen CS, Sorensen J, Primdahl J. Bed bath with soap and water or disposable wet wipes: patients' experiences and preferences. J Clin Nurs. 2019; 28: 2235-44. Available from: https://doi.org/10.1111/jocn.14825

12. Ahluwalia SC, Gill TM, Baker DI, Fried TR. Perspectives of older persons on bathing and bathing disability: a qualitative study. J Am Geriatr Soc. 2010; 58(3): 450-6. Available from: https://doi.org/10.1111/j.1532-5415.2010.02722.x 